\title{
QRTOTH - TRANSMISSÃO DO RESULTADO DA SEÇÃO ELEITORAL PELO PRÓPRIO MESÁRIO
}

\author{
Álvaro Sampaio Corrêa Neto ${ }^{1}$
}

Resumo: O presente artigo apresenta modelo complementar e alternativo à transmissão do resultado da seção eleitoral por meio da leitura do QR Code impresso ao final do boletim de urna. Também são apresentados os resultados obtidos com projeto piloto realizado nas Eleições Municipais de 2019.

Palavras-chave: Transparência. Inovação. Celeridade.

${ }^{1}$ Técnico Judiciário. Secretário de Tecnologia da Informação do TRESC. Mestre em Engenharia de Produção. 


\section{Desenvolvimento}

A disponibilização complementar das informações do Boletim de Urna ${ }^{1}$ no formato QR Code 2 , em conjunto com o aplicativo "Boletim na Mão", agregou mais transparência e confiabilidade ao processo eleitoral brasileiro. Considerando que, após o encerramento da seção, as informações constantes no Boletim de Urna (BU) são públicas, que o QR Code impresso no BU contém os resultados necessários à totalização e que os mecanismos de segurança utilizados são suficientes para assegurar a integridade e autenticidade de seu conteúdo, a proposta do projeto foi utilizar o poder da coletividade para transmitir os resultados de forma descentralizada a partir de um aplicativo móvel disponibilizado pela Justiça Eleitoral aos mesários, delegados de prédio ou qualquer cidadão que desejar participar desse processo.

Nesse cenário, o TRE-SC aplicou projeto experimental, no segundo turno das Eleições 2016, para que os próprios mesários, ou qualquer cidadão, transmitissem o resultado da seção eleitoral, de forma complementar e sem prejuízo aos procedimentos oficiais, em três cidades de Santa Catarina: Blumenau, Florianópolis e Joinville. Para tanto, foi desenvolvido e idealizado o projeto QRToth, com objetivo de ler e transmitir os dados constantes do QR Code impresso no BU para a Justiça Eleitoral. O objetivo desta inciativa experimental foi avaliar a viabilidade de aplicação do método de transmissão com a utilização de celular de qualquer pessoa.

O dia mais importante para a Justiça Eleitoral é o dia do pleito. A tensão existente nessa data aumenta ainda mais a partir das $17 \mathrm{~h}$ - momento a partir do qual os diversos procedimentos para encerramento das seções começam a ser executados. Um deles consiste na afixação de cópia do BU em local visível para dar publicidade do resultado da seção; outro, em retirar da urna a mídia de resultados (MR) para que os dados possam ser transmitidos à Justiça Eleitoral.

\footnotetext{
${ }^{1}$ NETO, Á. S. C. Transparência no processo eleitoral. Resenha Eleitoral - Revista Técnica, v. 1, n. 6, 2014.

${ }^{2}$ Vazquez-Briseno, M. ., Hirata, F. I. ., de Dios Sanchez-Lopez, J. ., Jimenez-Garcia, E. ., Navarro-Cota, C. ., \& Nieto-Hipolito, J. I. (2012). Using RFID/NFC and QR-Code in Mobile Phones to Link the Physical and the Digital World. Interactive Multimedia, 219-242. http://doi.org/10.1080/14626269109408287

${ }^{3}$ Boletim na mão: http://sticonhecimento.tse.jus.br/csele/informativos/eleicoes-2016/ Folder_Boletim_na_Mao.pdf/at_download/file
} 
Um dos modelos de transmissão dos dados baseia-se no transporte das mídias de resultados (MRs) do local de votação para o local onde serão lidas e totalizadas. Santa Catarina comumente utiliza diversas rotas de recolhimento com veículos rápidos para recolher apenas as MRs. Esta estratégia busca trazer mais celeridade ao processo de totalização, visto que a urna eletrônica e demais materiais são recolhidos posteriormente por veículos maiores e mais lentos.

Outro, alternativo e complementar ao modelo de recolhimento e transporte da MR, consiste em transmitir o resultado diretamente do local de votação. Para isso, normalmente utiliza-se a solução JEConnect ${ }^{4}$ que utilizando computadores de escolas e centros comunitários, estabelece um ambiente e conexão seguros com a Justiça Eleitoral para que a MR possa ser lida e transmitida, podendo, desta forma, evitar a utilização de motoboys para o recolhimento das MR. Este procedimento traz mais celeridade, porém aumenta a necessidade de recrutamento e seleção de pessoas aptas a operarem solução tecnológica.

Santa Catarina utiliza um pouco de cada modelo, de modo a trazer celeridade associada a custo e complexidade razoáveis, visto que existem vantagens e desvantagens em cada um deles. Assim, o objetivo deste artigo é apresentar um novo modelo de transmissão do resultado da seção pelo próprio mesário de modo a ser mais uma alternativa para um país de dimensões continentais, porque uma comparação entre os modelos de transmissão está além do objetivo deste artigo.

Este novo modelo, objeto deste artigo, consiste em transmitir diretamente da seção eleitoral a informação constante no QR Code impresso no BU, utilizando aparelhos celulares dos próprios mesários, considerando que, após o encerramento, a informação já é pública e os demais critérios de segurança para transmissão podem ser garantidos com os elementos constantes no QR Code e com características utilizadas no desenvolvimento do aplicativo.

Assim, dos três principais critérios de segurança da informação: confidencialidade, integridade e disponibilidade ${ }^{5}$; há necessidade de se garantir apenas os dois últimos pois a informação já se tornou pública. Par-

\footnotetext{
${ }^{4}$ JEConnect: http://sticonhecimento.tse.jus.br/grupos/je-connect/tutoriais-e-guias-operacionais/mapa-documental-da-jeconnect

${ }^{5}$ GOODRICH, M. T.; TAMASSIA, R. Introdução à Segurança de Computadores. [s.1.] Bookman, 2013.
} 
tindo deste princípio, os dados do BU podem ser transmitidos por qualquer pessoa, pois não há informação confidencial, sendo necessário utilizar mecanismos para preservar a integridade e a disponibilidade.

Visto que os resultados são transmitidos a partir da própria seção eleitoral, imediatamente após o encerramento e impressão do BU, este novo modelo traz mais celeridade à apuração e pode desonerar consideravelmente os custos de logística do recolhimento das MRs. A proposta possui uma série de vantagens, dentre as quais pode-se destacar:

- Celeridade: com a transmissão diretamente da seção eleitoral cada mesário transmite os votos apurados em sua seção eleitoral. Assim, quase que simultaneamente todas as seções podem transmitir o resultado à Justiça Eleitoral.

- Redução de custos: pode-se eliminar ou reduzir, significativamente, o uso de motoboys para recolhimento das mídias. Desta forma a urna poderia até ser recolhida no dia útil seguinte, diminuindo também o valor gasto na contratação de recolhimento das urnas, pois seria executada em dia útil.

- Mais confiabilidade: quanto mais pessoas transmitirem um mesmo BU maior o grau de confiança na transmissão daquela informação.

- Sem recrutamento e seleção de pessoas adicionais: como a transmissão é realizada pelos próprios mesários, não há necessidade de convocação adicional de pessoas especializadas.

- Desnecessidade de equipamentos adicionais: em função de a transmissão ser realizada com celulares dos próprios mesários, não é necessário a aquisição de equipamentos.

A segurança das informações a serem transmitidas pode ser garantida utilizando-se recursos utilizados nas demais etapas do processo eleitoral, ou seja, por meio da assinatura digital utilizada na geração do QR Code do BU, pode-se assegurar sua autenticidade, garantir que determinadas informações foram geradas por uma urna oficial e que seus dados não foram adulterados (integridade). 


\section{A solução desenvolvida}

A solução desenvolvida no projeto é composta por duas partes principais: o front-end e o back-end. Para a primeira parte, foi desenvolvido um aplicativo mobile para que os mesários que faziam a leitura do QR Code impresso ao final do BU, validassem e transmitissem os dados ao TRE-SC. Para a segunda parte, foi desenvolvido um serviço que consumia e validava novamente todos os BU transmitidos, armazenando-os em uma tabela para posterior análise. Por se tratar de um projeto experimental, sem regulamentação para totalização, os dados recebidos ficaram com acesso restrito até o término da apuração oficial e serviram apenas para estudo posterior.

Em função do pouco tempo disponível, o aplicativo QRToth foi desenvolvido apenas para a plataforma Android, a partir da versão 4.3, sendo utilizado o Android Studio 6 , ferramenta oficial e gratuita disponibilizada pelo Google. Para realizar a leitura do QR Code, foi utilizada a biblioteca Zebra Crossing: ZXing - BarcodeScanner7. Todas as transmissões de dados foram realizadas por meio de uma conexão criptografada entre o aplicativo e o TRE-SC, com a utilização de um certificado auto-assinado criado especificamente para este projeto. Além disso, foi utilizado o conceito de Material Design, de acordo com os modelos de padronização disponíveis no mercado.

As figuras 1 e 2 apresentam a tela principal do aplicativo mobile e o momento de leitura de um QR Code, respectivamente. Por se tratar de um aplicativo para uso por muitas pessoas, a usabilidade foi uma das premissas aplicadas ao desenvolvimento. Como o perfil dos potenciais usuários pode variar muito, a automatização de procedimentos de leitura e envio foi adotada de maneira que o uso do aplicativo seja intuitivo e com pouca interação. A utilização do aplicativo consiste basicamente em posicionar o QR Code dentro da área indicada na tela de leitura e aguardar seu reconhecimento automático. Após a leitura do QR Code, os dados são transmitidos automaticamente, em segundo plano, para o TRE-SC. A transmissão pode ocorrer tanto pela rede de dados celular como pelo Wi-Fi, por este motivo, é imprescindível que haja conexão com a Internet.

\footnotetext{
${ }^{6}$ Android Studio - https://developer.android.com/studio.

${ }^{7}$ ZXing - BarcodeScanner - https://github.com/dm77/barcodescanner.
} 


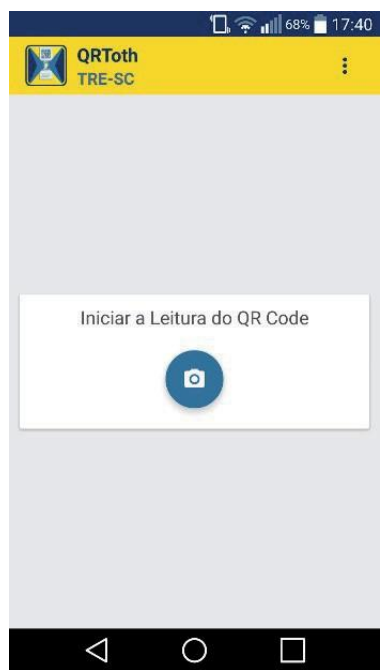

Figura 1: Tela Inicial sem leituras realizadas

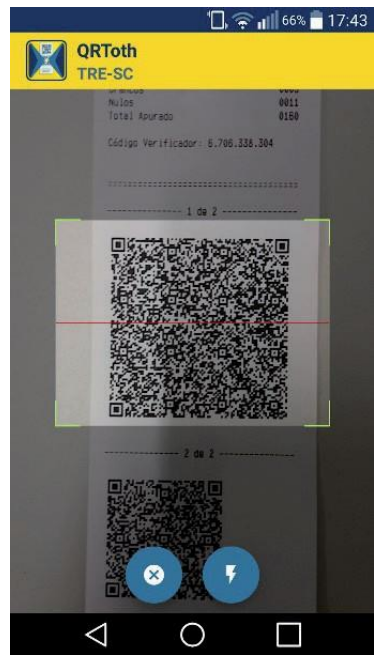

Figura 2: Realizando a leitura do QR Code

O aplicativo também está preparado para a leitura de BU com mais de um QR Code, conforme apresenta a figura 3, na qual solicita-se ao usuário o posicionamento da câmera no segundo código. No entanto, deve-se garantir que os dados estão íntegros antes da transmissão. Para isso são realizadas validações de Hash e Assinatura Digital conforme o manual de instruções do TSE, no qual a assinatura digital é verificada com a chave pública disponibilizada, neste caso, para o Estado de Santa Catarina. Assim que validados, os dados são enviados para um servidor nas dependências do TRE-SC, onde são validados novamente pela parte back-end do projeto.

Em função de ser um projeto experimental, todo e qualquer BU transmitido e válido é aceito, ou seja, um determinado celular pode ler tantos BU quantos desejar e também um mesmo BU pode ser lido uma ou mais vezes por celulares diferentes. A figura 4 apresenta a tela contendo a lista de BU que um determinado celular leu e transmitiu ao TRE-SC. 


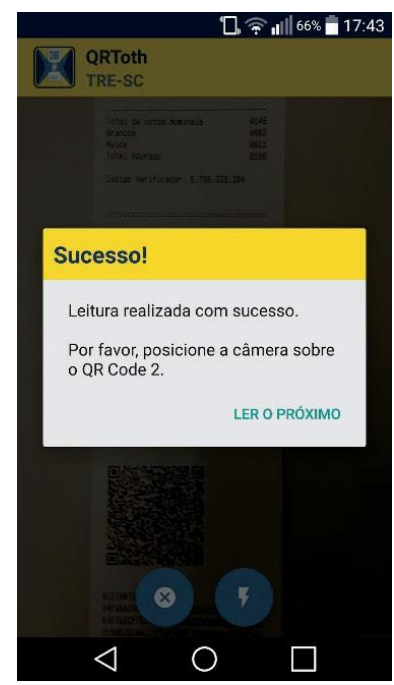

Figura 3: Leitura realizada com sucesso

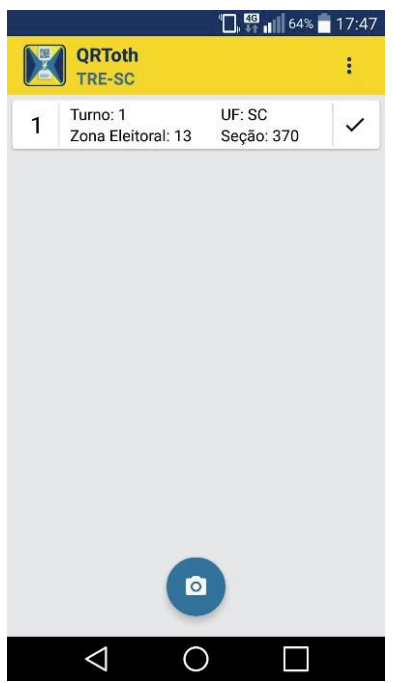

Figura 4: Leitura enviada para o TRE-SC

A parte de back-end é composta por diversas tecnologias e linguagens. Um serviço Web desenvolvido em Java, rodando em servidor Jboss, recebe as conexões dos celulares, valida novamente o BU transmitido e grava o resultado em disco em formato JSON. Este arquivo é posteriormente transmitido a outro computador por meio do comando rsync, para ser importado em um banco de dados por um script escrito em linguagem Ruby, conforme apresenta a figura 5.

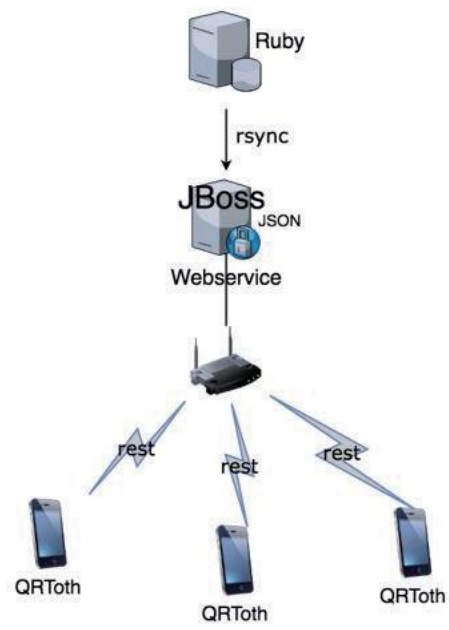

Figura 5: Arquitetura da parte back-end 


\section{Resultados obtidos}

O QRToth foi aplicado de forma experimental e não obrigatória no segundo turno das Eleições 2016 em três cidades de Santa Catarina: Blumenau, Florianópolis e Joinville. Por não estar previsto nenhuma atividade de treinamento dos mesários entre o primeiro e segundo turno, a estratégia para divulgação do aplicativo foi a comunicação do projeto aos chefes de cartórios das zonas envolvidas e a produção de um folder explicativo que foi colocado na pasta dos mesários. Apenas com estas atividades de divulgação o projeto teve um total de 431 pessoas que utilizaram o aplicativo no dia do pleito, conforme distribuição ilustrada pelo gráfico 1 .

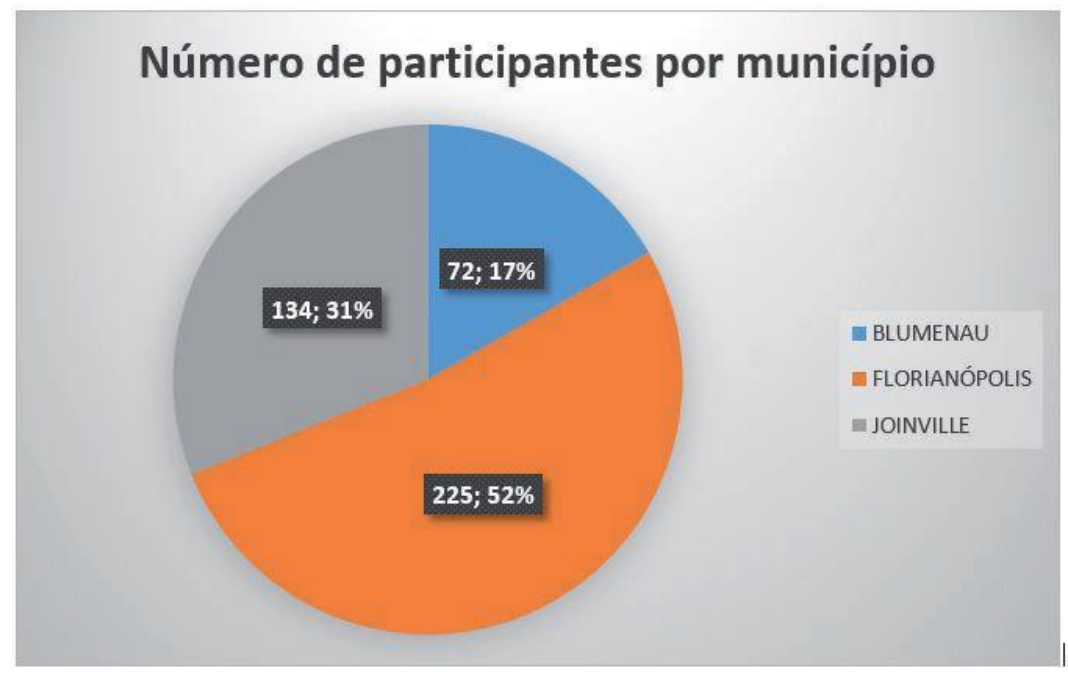

Gráfico 1: Número de participantes por município

Mesmo sendo opcional e com poucas ações de divulgação, foram transmitidas $42,46 \%$ das seções esperadas por meio do QRToth, com destaque para o município de Blumenau que transmitiu 98\% das seções, conforme ilustra o gráfico 2. Este destaque deve-se ao empenho dos chefes de cartórios que utilizaram estratégias adicionais como a utilização de um grupo de Whatsapp dos mesários para divulgar e fomentar o uso do aplicativo. 


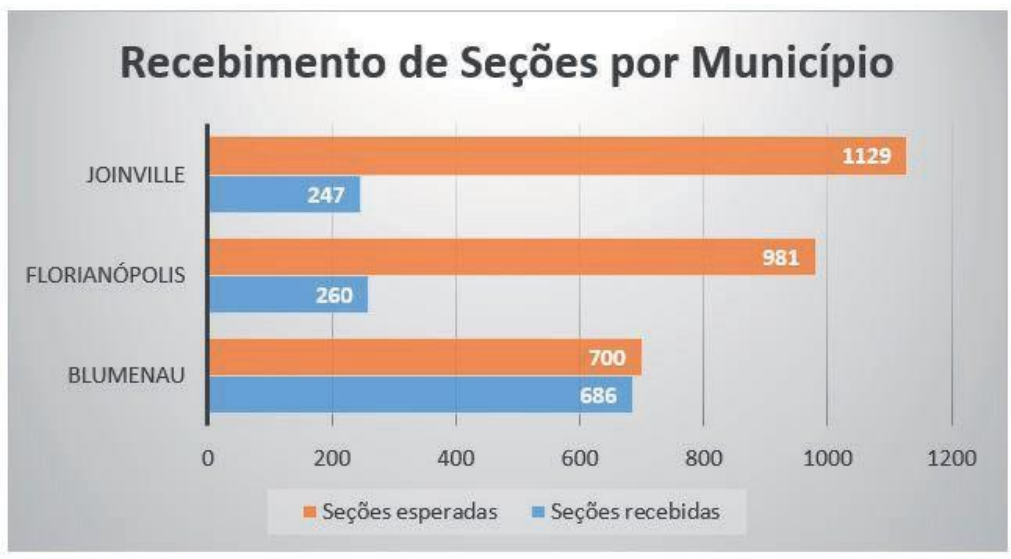

Gráfico 2: Recebimento de Seções por Município

O gráfico 3 apresenta a comparação entre o recebimento que empregou o QRToth e o recebimento da apuração oficial, no município de Blumenau, que utilizou recolhimento de mídia com motoboy e contou também com 4 pontos de transmissão com JEConnect. Vale destacar que o primeiro BU foi recebido no QRToth às 17:01h, enquanto o primeiro da apuração oficial foi recebido às 17:09h. Além disso, cabe destacar que 50\% das seções do município já estavam transmitidas em 12 minutos; e 90\% das seções em que se utilizou o aplicativo foram transmitidas em 40 minutos.

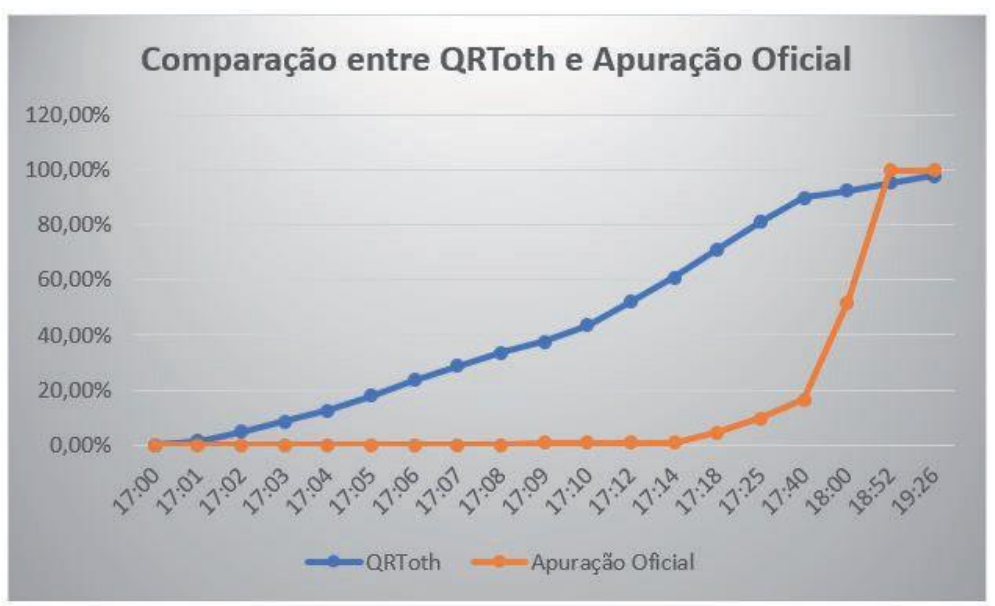

Gráfico 3: Comparação entre QRToth e Apuração Oficial 


\section{Conclusão}

O QRToth demonstrou-se viável como alternativa complementar aos modelos de transmissão de boletins de urna existentes e com excelente aplicabilidade à Justiça Eleitoral, conforme os resultados obtidos no proje- to experimental. Além de utilizar o poder da coletividade, não exige novas convocações e pode reduzir os custos com logística. Assim, é recomendávelque, em um país com dimensões continentais, se possa aplicar o modelo de transmissão de boletins de urna mais adequado à realidade de cada local de votação.

O caráter experimental e o tempo disponível para o projeto nãopermitiram explorar uma série de questões que devem ser abordadas antes de qualquer adoção oficial. Alguns locais de votação não possuem cobertu- ra de sinal de celular e precisariam ser mapeados previamente, de modo a prover alguma forma de comunicação com a Internet ou utilização de outro modelo de transmissão do BU. Além disso, alguns mesários não possuem plano de dados no celular. Portanto, faz-se necessário que o endereço para onde serão transmitidos os boletins de urna estejam isentos de cobrança de quem os acessa, assim como alguns bancos e outras instituições já o fazem.

As questões de segurança e ataque de negação de serviço também devem ser mais bem exploradas. A exibição de um QR Code na tela da urna contendo o endereço para onde o aplicativo transmitirá o BU é umaalternativa que poderia ser utilizada para minimizar possibilidade de ataque de negação de serviço. Também poderia ser exibido na tela o QR Code, queé impresso ao final do BU, de modo que a leitura dos dados do BU possaocorrer mesmo que haja qualquer problema com a impressora da urna.

Por fim, cabe ressaltar que este trabalho e artigo só foram viáveis pelo empenho e competência de toda a equipe da Secretaria de Tecnologia da Informação e do apoio e incentivo da Direção-Geral e corpo diretivo.Além disso, o sucesso da aplicação do projeto em Blumenau se deve à de-dicação dos chefes de cartório que, por conta própria, apoiaram incondi-cionalmente a ideia. 